\title{
Access to Vaccines and the Vaccine Industry - An Analysis
}

\section{K V Balasubramaniam* and Dr V. Sita}

School of Management Studies, University of Hyderabad, India

*Corresponding author: K V Balasubramaniam, Research Scholar, School of Management Studies, University of Hyderabad, Hyderabad, 500032, India, E-mail: kvbala2711@hotmail.com

Rec date: 13 Dec 2014; Acc date: 19 Feb 2014; Pub date: 23 Feb 2014

Copyright: $\odot 2014$ Balasubramaniam KV, et al. This is an open-access article distributed under the terms of the Creative Commons Attribution License, which permits unrestricted use, distribution, and reproduction in any medium, provided the original author and source are credited.

\begin{abstract}
Access to vaccines is a critical issue in ensuring the health of children, especially in the developing countries. Access is currently limited due to limited money available for vaccine procurement, high prices of new vaccines for existing and emerging diseases and poor health delivery infrastructure in developing countries. The vaccine industry has only paid lip service to the cause of immunization of the world's children. They have kept their profit maximization objective foremost even in the interactions with the international agencies and with health partnership initiatives. However, if they avoid such selfish pursuits and look at shared value with society, much can be gained in the immunization of children and their health. The vaccine industry must shed its reticence, respond to the economic and technological demands of immunization and work towards making immunization affordable and accessible to all. This paper scans the vaccine industry and analyzes the issues concerning vaccine access and the role played by the industry.
\end{abstract}

Keywords: Vaccines; Vaccine access; Immunization; Developing countries; Vaccine industry; Social responsibility

\section{Vaccine Access}

Vaccines offer the most cost effective and equitable health interventions known to man. Vaccines save millions of lives, mostly infants and children, from several dreaded diseases which cause mortality and morbidity. Thanks to vaccines and systematic immunization, the dreaded small pox disease has been eradicated; and the polio disease is seeing its final death knell. It is estimated that vaccines avert about 2-3 million deaths each year in all age groups and protect $83 \%$ (107 million) of infants worldwide from vaccine preventable diseases [1].

Therefore, it would seem that the vaccine business should be thriving. This is only partly true. The vaccine business thrives in developed countries, but not in developing countries and least developed countries. This is on account of the fact that immunization of the world's children, and to lesser extent adults, is bogged by a number of issues. The chief issue is about access to vaccines by the majority of the world's population living in the developing and least developed countries. Access is limited, inter alia, due to limited money available for vaccine procurement, high prices of new vaccines for existing and emerging diseases and poor health delivery infrastructure in developing countries [2].

As a result, there is a big divide between vaccines available for immunizing children in developed countries and the children in developing and least developed countries. The former have access to vaccines to protect against at least 12 diseases, whereas the latter have limited access to vaccines to protect only against 6 diseases. Even this is provided by the Governments as a public health measure, thanks to the initiative of the World Health Organization (WHO) through its Universal Immunization Programme (UIP) initiative launched in 1974. Much of the funding for immunization also comes from munificent donors.

\section{Immunization Progress}

The progress on immunization till 2000 was rather slow with the coverage for DTP 3rd dose (this is the commonly used measure of immunization coverage) hovering around $70 \%$ in the decade till 2000 [3]. The availability of the six vaccines was also an issue as the main manufacturers, who were mostly multinational companies (MNCs) in the developed world, had withdrawn from manufacturing of these vaccines due to profitability issues in their supplies of these vaccines to UNICEF [4]. This created a crisis situation for immunization.

In September 2000, leaders of 190 countries signed the United Nations Millennium Declaration which committed the international community to eight key development goals, which aimed at reducing poverty and improving human development. These goals are known as the Millennium Development Goals (MDGs). MDG 4 calls for a drastic reduction of deaths of children under five years of age with a two third drop in under-five mortality rate between 1990 and 2015, from 12.8 million deaths to 4.3 million deaths [5]. This was possible only by better immunization practices.

The other two MDGs also would be achieved through emphasis on immunization as a cost effective intervention. These are improving maternal health by reducing the maternal mortality ratio by three fourth between 1990 and 2015 (MDG 5); and combating HIV/AIDS, malaria and other diseases (MDG 6) by halting and beginning to reverse the incidence of malaria and other major diseases.

Realizing that global immunization rates were stagnating and that the MDG goals cannot be sustained in poor countries, the Global Alliance for Vaccines and Immunization (GAVI) - a public-private global health partnership of philanthropists and governments, took up the challenge of providing immunization and access to vaccines to the very poor countries in the world. GAVI has so far funded $\$ 4.6$ billion to over 70 countries for various immunization programmes [6]. This has resulted in immunizing 370 million children and averting death of 5.5 million children in the least developed and developing countries [7]. 
Page 2 of 5

The WHO on its part, realizing that immunization means much more than providing vaccines and improving immunization delivery systems, also responded to this challenge by adopting the Global immunization Vision and Strategy ( GIVS) for the decade 2006 to 2015. GIVS has four main aims - to immunize more people against more diseases; to introduce a range of newly available vaccines and technologies; to integrate other critical health interventions with immunization; and to manage vaccination programmes within the context of global interdependence [8].

These efforts have yielded good results. The vaccination coverage, which was stagnating a around $70 \%$ for a decade has now moved up to $83 \%$. Deaths due to measles have sharply declined from 873000 deaths in 1999 to 345000 in 2005, surpassing the goal to halve the deaths by 2005 [9]. There is increasing use of vaccines for diseases beyond the six in EPI, to Hepatitis B, Haemophilus Influenza B, Mumps, Rubella, Meningococcus, Pneumococcus, Rotavirus etc.,

\section{Sustaining Immunization}

While much ground has been covered, there is still a lot to be done for immunization. The main problem that GAVI and other agencies are faced with is sustaining the programme and bringing in new diseases under vaccination coverage. This has been made arduous due to limited funding available. This is notwithstanding the efforts to reduce costs of vaccines and immunization infrastructure through centralized system of procurement through the United Nations Children's Emergency Fund (UNICEF); supporting manufacturers from the developing countries who have a demonstrated ability to offer quality vaccines at lower prices; and funding new vaccine research for unmet immunization needs.

In 2011, the UNICEF procured about 2.5 billion doses of these vaccines worth USD 1 billion with funding from GAVI and other donor countries for supply to the least developed and some developing countries [10]. These vaccines are cheap, and as a result, the USD 1 billion in value represents just $4 \%$ by value but $40 \%$ by volume of all human vaccine doses marketed in the world. However, the newer vaccines are expensive, in dollars per dose compared to cents per dose for the older vaccines. With limited number of vaccine companies engaged in research and with the regulatory systems becoming more arduous, new vaccines will get even more costly.

It is estimated that GAVI needs US $\$ 8.4$ billion to support further immunization in about 73 countries till 2016. However, it has secured pledges and contributions of only $40 \%$ of this amount. This poses serious issues about sustaining immunization in poor countries [11]. GAVI has tried to overcome this by unique funding mechanisms such as the International Funding Facility for Immunization (IFFI) which uses long term donor pledges for bonds issued to investors in the capital markets; Advance Market Commitments (AMCs) which tie up donor commitments to attract new vaccine development at low prices and in sufficient quantities; and the GAVI Matching Fund to leverage contributions from corporations, foundations and individuals.

However, all this has met with only limited success, largely on account of the oligopoly situation in the vaccine industry where about five companies - GSK, Merck, Sanofi-Pasteur, Pfizer and Novartis control $80 \%$ of the market; and also on account of the inability of the developing country manufacturers to invest both in both human capital and financial resources to develop technologies for new vaccines and in carrying out costly and time consuming clinical trials in a strict regulatory environment.

\section{Response of the Vaccine Industry}

Given this situation, one would expect the vaccine industry, and particularly the big five players, to take a leading role in improving access to vaccines. This could be in terms of developing vaccines used against dreaded diseases, by keeping prices affordable and making available technology to low cost producers so that the larger population may benefit. Sadly, they have not played their role. On the other hand, they have tried to usurp the funding for new vaccine development of GAVI, have shied away from reducing prices and have been reluctant to allow access to technology to low cost producers.

Some examples illustrate this situation. In an article in Human Vaccines, Donald W Light criticized the Advance Market Commitment (AMC) mechanism which was first tried for development of a low cost pneumococcal vaccine as impractical and one which favored the few multinational pharmaceutical companies that develop vaccines over smaller companies who could not afford the development costs. Despite a proposed buyout worth a few billion dollars, the AMC design included no arrangement for acquiring IP rights or technology transfer. He estimated that at a price of US $\$ 5$ per dose committed for purchase with US $\$ 1$ as co-payment, about US \$ 1 billion out of the US $\$ 1.5$ billion spent on the AMC would actually accrue to the companies [12].

Other critics of the Pneumococcal AMC pointed out that there was no real new vaccine being developed as the vaccine was already in the market as Prevnar of Wyeth (now part of Pfizer); and that the two versions of the vaccine with wider coverage of serotypes - by PfizerWyeth and Merck, were already in the final stages of development and close to gaining market approval, and that it would be possible to procure the vaccine cheaper through the normal procurement mechanism of UNICEF for GAVI [13].

The other example is of new vaccines, such as Rotavirus. Both Merck and GSK developed the vaccine. The clinical trials for these vaccines were done in the developing countries. The disease also affects children in the developing and least developing countries, with about 500000 deaths due to the disease mainly in developing countries. The vaccine is being marketed at about $\$ 75$ per dose USA under the Vaccines for Children Programme (VFC) for programmes [14]. This level of price is highly unaffordable in the developing countries. Merck launched the vaccine in India at a price of $\$ 18$ per dose, which is also beyond the reach of a large majority of potential users.

It has also been reported that the other manufacturer - GSK, was trying to get GAVI to take the Rotavirus vaccine into the advance market commitment programme and that the choice for GAVI for the AMC was between the pneumococcal vaccine and the Rotavirus vaccine, both which were already in the market [15]. It was not until the Programme for Appropriate Technologies in Health (PATH), an international non-profit organization, was able to develop this vaccine in partnership with an Indian company and also due to the work of other Indian companies, that there was hope of the price being brought down to about $\$ 1$ per dose. Until such time the vaccines are supplied to UNICEF by the Indian companies, UNICEF will be paying a price of $\$ 5$ per dose for this vaccine.

Similar is the case with pricing of an important vaccine in the immunization portfolio - the pentavalent vaccine which offers protection against five diseases - diphtheria, pertussis, tetanus, haemophilus influenza and hepatitis $\mathrm{B}$. This vaccine was being procured by UNICEF from two MNC companies - Sanofi Pasteur and GSK at a negotiated price of around $\$ 3.5$ per dose. It was not as if the 
pentavalent vaccine was a new product. It was first introduced in 1993 when the development costs were much lower. However, the prices to UNICEF for this important vaccine continued to be high and it was not until a few developing country manufacturers entered the fray that the price at which this vaccine was being procured by UNICEF for GAVI fell from $\$ 3.5$ to $\$ 1.75$ per dose in 2012 [15].

On the technology side, the reluctance by multinational companies to transfer, at least partly, technology to the developing world manufacturers for manufacture of vaccines for important diseases is evident in the case of the Injectable Polio vaccine (IPV). Eradication of polio is now at the end game stage. This has been possible due to sustained pulse campaigns in the most affected countries by large scale involvement of health workers and para medical staff, supported by extensive awareness and promotional campaigns. The vaccine used oral live polio vaccine is also cheap, costing just 18 US cents per dose to UNICEF. Funding for the eradication programme has been through generous grants from several governments and GAVI. In a few years' time polio is expected to be eradicated.

However, it is not as if there would be no vaccines required once polio is eradicated. WHO recommends that, post eradication, the vaccine to be used has to be the injectable polio vaccine (IPV), which is inactivated. As compared to the oral live polio vaccine, which runs the risk of reversion of the virus from the vaccine itself, the injectable vaccine would be safer. Once implemented, there would be huge opportunities for manufacturers of the injectable polio vaccine since large volumes can be sold in the developing and least developing countries.

However, the technology for the well accepted Salk strain injectable polio vaccine is closely held by about five MNC and developed country manufacturers. They have been reluctant to part with technology, although their manufacturing capacities to serve large markets such as India are limited. This left the WHO with no option but to help developing country manufacturers develop the Sabin strain of IPV. However, this is time consuming and costly due to long regulatory pathways and due to the fact that the Sabin strain being an attenuated strain, yields in manufacture would be lower as compared to the Salk strain. Were the existing manufacturers to be magnanimous, they could have chosen to work with WHO or the Governments in developing countries for transfer of technology to manufacture the Salk IPV vaccine in large scale.

\section{Counter Argument}

It could be well argued that the established developed country manufacturers, particularly the big five, keep their commercial interests in mind in choosing to keep prices high, or in not willing to transfer technologies. Profit maximization and maximizing the returns to shareholders would be their major motives in business. However, it must also be appreciated that there has to be a noble element for a player especially in the immunization business and a greater sense of corporate social responsibility. Businesses in the modern age have to look at how they give back to society, not merely in terms of certain Corporate Social Responsibility (CSR) projects, but how the business as a whole would help in social development. Keeping prices low for those who cannot afford and developing new products which society direly needs make a huge impact which no amount of numerous CSR projects can. As Michael Porter put it, "Businesses must reconnect company success with social progress. The solution lies in the principle of shared value, which involves creating economic value in a way that also creates value for society by addressing its needs and challenges [15].

MNC companies such as GSK counter the high price argument by stating that that they follow a pricing model which keeps the prices high in developed countries and at the same time, keep them much lower in developing countries. They refer this to tiered pricing. This, they state, helps them keep the costly research going. While this may be true from their perspective, when looked at from a developing country perspective, it does not make sense since from an affordability view point, their prices are still highly unaffordable. As case in example, GSK's vaccines such as for Hepatitis B, are sold at multifold times the prices of its competitors in countries such as India and China. Likewise, the introduction of the pneumococcal vaccine in India by Wyeth in 2008, was at a highly unaffordable price [16].

The counter argument for technology transfer from MNCs has been that they have transferred technologies to some countries such as Brazil for such vaccines as Haemophilus type B (Hib) and Rotavirus. However, it must be mentioned here that these are mainly arrangements for filling of bulk antigens mainly on account of restrictions on direct imports of vaccines by the Govt of Brazil. The arrangements have also been with Govt companies/institutes and targeting, in exchange, the national immunization programmes which offer large volumes at moderately high prices.

The counter argument of shareholder capitalism would therefore be weak when we look at the more egalitarian demands on a vaccine business which deals with the life and health of children, most of whom live in developing and least developing countries. This argument withers when we look at the profitability of the companies which make these vaccines.

\section{Vaccine Industry Profitability}

In the US $\$ 150$ billion global biopharmaceutical market, vaccines constitute the second biggest segment after therapeutic products, accounting for USD 30 billion in sales in 2012 and growing by about 7 $\%$ p.a [17]. Until a few years ago, vaccines were not counted as potential block buster products because they were seen as low priced products used largely by Governments in immunization programmes. The huge success of Pneumococcal vaccine - Prevnar of Wyeth (now part of Pfizer) and - the Human papilloma virus vaccine (HPV) of Merck to protect against cervical cancer brought a paradigm shift in the market and this led to new vaccine candidates being developed and launched.

The vaccine industry has an oligopoly character in which a handful of companies compete. Even here, each company comes to occupy a niche in the market, focusing on a few disease areas. The entry barriers to the business are high due to, inter alia, the nature of technology involved (biotechnology), long and arduous regulatory processes and high capital investment. As a result, competitiveness is reduced to two, or at best three players, for the newer vaccines that are brought to the market. Not surprisingly therefore, prices are high, as also the profitability of the companies.

Table 1 presents some idea of the profitability of the companies that are in the vaccine business. 
Page 4 of 5

\begin{tabular}{|l|l|l|l|l|l|l|l|}
\hline Company & Unit of A/c & Sales 2012 & \multicolumn{2}{l|}{ Sales from Vaccines } & \multicolumn{2}{l|}{ Profit Before Tax } & $\begin{array}{l}\text { Contribution } \\
\text { Vaccines to Op. Profit }\end{array}$ \\
\hline & & & Value & $\%$ & Value & $\%$ & \\
\hline Sanofi & Mio Euros & 34947 & 3897 & 11.1 & 6337 & 18.1 & 10.1 \\
\hline GSK & Mio Pounds & 26431 & 3325 & 12.6 & 7635 & 28.9 & 14.0 \\
\hline Merck & Mio US \$ & 47267 & 1631 & 3.4 & 6299 & 13.3 & NA \\
\hline Pfizer & Mio US \$ & 58986 & 4117 & 7.0 & 12080 & 20.5 & NA \\
\hline Novartis & Mio US \$ & 56673 & 1858 & 3.2 & 9618 & 17.0 & -0.5 \\
\hline
\end{tabular}

Table 1: Profitability of Major Companies in the Vaccine Business in 2012

\section{Source: Published Company Annual Reports. NA : Not Available}

It can be noted from the Table that vaccine profitability is as high as pharmaceuticals and in fact, even higher for companies such as Sanofi and GSK. For Sanofi, while the profitability of the pharmaceutical business has reduced in 2012 as compared to 2011, the profitability of the vaccine business has actually improved. In the case of Novartis, the profitability of the vaccine business has actually reduced in the last two years and this has been attributed to revenue loss due to production constraints.

It is pertinent to mention here that the profitability of even a leading developing country player such as Serum Institute is as high as $41 \%$ (post tax) on sales revenues of INR 17 Bio (\$ 309 Mio) posted in 2011 [18]. It can thus be reasonably assumed that vaccines are as profitable as the hugely profitable pharmaceutical business for most of the players in the industry.

\section{New Vaccine Focus}

Another aspect of access to vaccines is how the industry looks at vaccines for diseases affecting the developing world. The World Health Organization (WHO) has identified seventeen conditions as "neglected tropical diseases" which cover bacterial, viral and parasitical infections [19]. They result in about 600000 deaths annually. MNC companies have no interest in developing vaccines for these diseases since there is no ready commercial markets for vaccines for these diseases that would justify the high research costs. An article by Peter Hotez notes that, save for one vaccine - Dengue for which MNC companies are developing vaccines, work on developing vaccines for the remaining diseases is actually being carried out by government and academic research institutions [20].

It is pertinent to mention here that the successful Meningitis A vaccine development programme by the Meningitis Vaccine Project was born out of a partnership between the Gates Foundation and PATH after no developed country vaccine manufacturers came forward to develop the vaccine. It was left to an Indian company Serum Institute to offer to sell the vaccine at less than 50 cents a dose and this made a critical difference [21,22].

\section{Lip Service to Vaccine Access}

From the foregoing discussions, it is not difficult to surmise that the vaccine industry has only paid lip service to the cause of immunization of the world's children. They have kept their profit maximization motives foremost even in their interactions with the international agencies and health partnership initiatives. On the other hand, they have attempted to usurp the funding of these agencies for their commercially established products. They have also shied away from developing 'antipoverty vaccines'. They have on the other hand pushed the agenda for introduction of vaccines developed by them for use in the developing countries.

The vaccine industry must have a moral responsibility to the cause of poor children in the least developed and developing countries. This cannot be left to the governments and international non-profit agencies espousing the cause of immunization. Diseases have no boundaries in a globalized world. They can equally affect both the developing and developed countries. There are both direct and indirect costs sustained on account of this. The vaccine industry cannot be reticent about this and sit on the fence, looking at only how opportunities can be commercially tapped. They have to contribute to vaccine access as part of their social responsibility.

\section{Conclusion}

There is a dire need now, more than before, to espouse the cause of cost effective immunization in the developing world. There is need to look at how new vaccines can be developed for neglected diseases. Health of people, more so, of children from the poorest regions of the world needs a strong push. This push can gain strength if the vaccine industry sheds its reticence and contributes to both the economic and technological demands of immunization.

\section{References}

1. WHO (2013) Immunization surveillance, assessment and monitoring. Geneva.

2. Paul Wilson (2010) Giving Developing Countries the Best Shot: An Overview of Vaccine Access and R\&D. Medecins Sans Frontieres 7.

3. WHO, UNICEF (2013) Immunization Summary, A Statistical Reference Containing Data Through 2012. Geneva.

4. Lisa Nainggolan (1997) Global Immunization-Realizing an Impossible Dream. Scrip Magazine Report.

5. WHO, UNICEF, World Bank (2009) State of the World's Vaccines and Immunization. (3rd edn), WHO, Geneva 5-6.

6. GAVI Alliance (2013) Disbursements by Country. GAVI Alliance, Geneva.

7. GAVI Alliance (2013) GAVI's Impact. Geneva

8. WHO (2005) Global Immunization and Vision Strategy 2006-2015. Geneva.

9. WHO, UNICEF, World Bank (2009) State of the World's Vaccines and Immunization. (3rdedn). Geneva 123-124.

10. UNICEF (2013) Vaccine Price Data.

11. GAVI Alliance (2013) GAVI Facts and Figures. GAVI Alliance, Geneva. 
Citation: Balasubramaniam KV, Sita V (2014) Access to Vaccines and the Vaccine Industry - An Analysis. J Vaccines Vaccin 5: 218. doi: 10.4172/2157-7560.1000218

Page 5 of 5

12. Donald W Light (2011) Saving the Pneumococcal AMC and GAVI. Human Vaccines 7: 138-141.

13. Paul Wilson (2010) Giving Developing Countries the Best Shot: An Overview of Vaccine Access and R\&D. Médecins Sans Frontieres 9.

14. Stephenne J (2011) Vaccines as a global imperative--a business perspective. Health Aff (Millwood) 30: 1042-1048.

15. CDC (2013) Vaccines for Children Program. Atlanta.

16. Michael E Porter, Mark R Kramer (2011) Creating Shared Value. Harvard Business Review 52-67.

17. Debarshi Dasgupta (2008) Immunity to Reason. Outlook 8: 20-22.
18. Sunxiaodong (2016) World Preview 2016: Beyond the Patent Cliff. Evaluate Pharma.

19. Jyoti Datta PT (2012) What Makes Serum Click. Business Line Report.

20. WHO (2012) The 17 Neglected Tropical Diseases. WHO, Geneva.

21. Hotez P (2011) A handful of 'antipoverty' vaccines exist for neglected diseases, but the world's poorest billion people need more. Health Aff (Millwood) 30: 1080-1087.

22. Bishal DM, Champion C, Steele M, Thompson L (2011) Product Development Partnership Hit Their Stride: Lessons from Developing a Meningitis A Vaccine for Africa. Health Aff (Millwood) 6: 1058-1064. 